\title{
Angioimmunoblastic lymphadenopathy with dysproteinaemia (AILD) and sicca syndrome
}

\author{
Y J BIGNON, ${ }^{1}$ A JANIN-MERCIER, ${ }^{2}$ J J DUBOST, ${ }^{1}$ J M RISTORI, \\ Y FONCK, ${ }^{2}$ J C ALPHONSE, ${ }^{3}$ AND B J SAUVEZIE
}

From the Departments of ${ }^{1}$ Rheumatology, ${ }^{2}$ Pathology, and ${ }^{3}$ Nephrology, Centre Hospitalier et Universitaire de Clermont-Ferrand 63003, Clermont-Ferrand Cedex, France

SUMmarY We report a case of AILD and sicca syndrome. The patient had presented with renal insufficiency, lymphadenopathy, hepatosplenomegaly, polyclonal hypergammaglobulinaemia, dryness of the eyes and mouth. Lip biopsy specimens showed an unusual cellular infiltrate similar to his kidney lesions. Data from the eight previously reported cases support the hypothesis that the association is a distinct pathological entity differing from pseudolymphoma and malignant lymphoma, which occur in the course of Sjögren's syndrome. The recognition of AILD is important because lymphoproliferation may lead to death after a few months.

Key words: lymphoma, Sjögren's syndrome, renal insufficiency.

Angioimmunoblastic lymphadenopathy with dysproteinaemia (AILD) is a lymphoproliferative disorder characterised by constitutional symptoms, rash, hepatosplenomegaly, dysproteinaemia, and generalised lymphadenopathy. ${ }^{1}$ In the lymph nodes the histological findings should meet three criteria: (a) extensive alteration of the nodal architecture; (b) abundance of small vessels; and (c) polyclonal proliferation of immune reactive cells.

The outcome of the disease is unpredictable, but the median survival is only two years. Although the pathogenesis is unclear, several features suggest that AILD is a hyperimmune disorder. ${ }^{2}$ Accordingly, AILD shares several features with systemic lupus erythematosus including arthralgia or arthritis. ${ }^{3}$ The association of AILD and Sjögren's syndrome has also been reported in eight instances, ${ }^{4-10}$ but its significance may have been misunderstood. In Sjögren's syndrome a spectrum of benign to malignant lymphoproliferation has been proposed. ${ }^{11}$ 'Pseudolymphoma' occupies the middle of this spectrum. AILD was thought to belong to this type of lymphoid involvement in Sjögren's syndrome, ${ }^{4}$ but

Accepted for publication 11 November 1985 .

Correspondence to Dr Y J Bignon, Department of Rheumatology. Centre Hospitalier et Universitaire de Clermont-Ferrand 63003 , Clermont-Ferrand Cedex, France. certain clinical and histological features, as documented in our patient, suggest that the association may be a distinct pathological entity.

\section{Case report}

A 70 year old male presented with fatigue, anorexia, and weight loss. He had had diabetes mellitus and sicca syndrome for three years. On examination he was found to have generalised lymphadenopathy, hepatosplenomegaly, salivary gland swelling, xerostomia, and keratoconjunctivitis. There was no arthralgia, fever, or skin lesion but a past history of unexplained pruritus. Schirmer's test and salivary scintiscan were markedly abnormal. Proteinuria $(2.4 \mathrm{~g} /$ day $)$ and a decreased glomerular clearance (creatinine $12 \mathrm{ml} / \mathrm{min}$ ) indicated renal involvement. Anaemia ( $\mathrm{Hb} 87 \mathrm{~g} / \mathrm{l}$ ) and a raised erythrocyte sedimentation rate $(130 \mathrm{~mm} / 1 \mathrm{st} \mathrm{h})$ were also noted. Serum protein was $10.2 \mathrm{~g} / 100 \mathrm{ml}(102 \mathrm{~g} / \mathrm{l})$, with a gammaglobulin of $6.0 \mathrm{~g} / 100 \mathrm{ml}(60 \mathrm{~g} / \mathrm{l})$ Immunoglobulin $G$ was $5.5 \mathrm{~g} / 100 \mathrm{ml}(55 \mathrm{~g} / \mathrm{l})$, immunoglobulins $\mathbf{A}$ and $\mathbf{M}$ were normal. Immunoelectrophoresis of serum and urine samples did not show any monoclonal component. Total haemolytic complement was low $(20 \%)$ : C3 $20 \mathrm{mg} / 100 \mathrm{ml}$ $(200 \mathrm{mg} / \mathrm{l}), \mathrm{C} 43.8 \mathrm{mg} / 100 \mathrm{ml}(38 \mathrm{mg} / \mathrm{l})$, with circulating $\mathrm{C} 3 \mathrm{~d}$. Immune complexes were abundant 


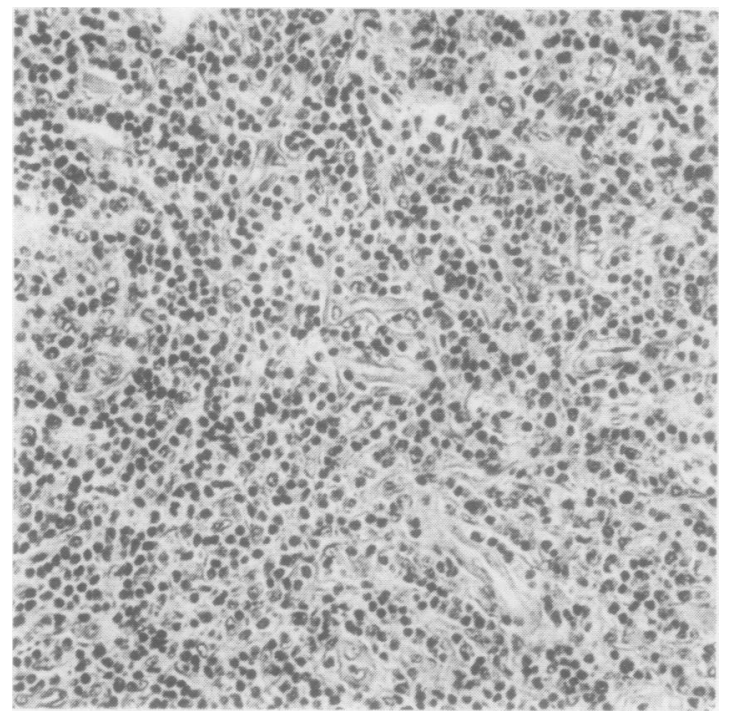

Fig. 1 Lymph node $(\times 210)$. The nodal architecture has been destroyed by a lymphoplasmacytic infiltration.

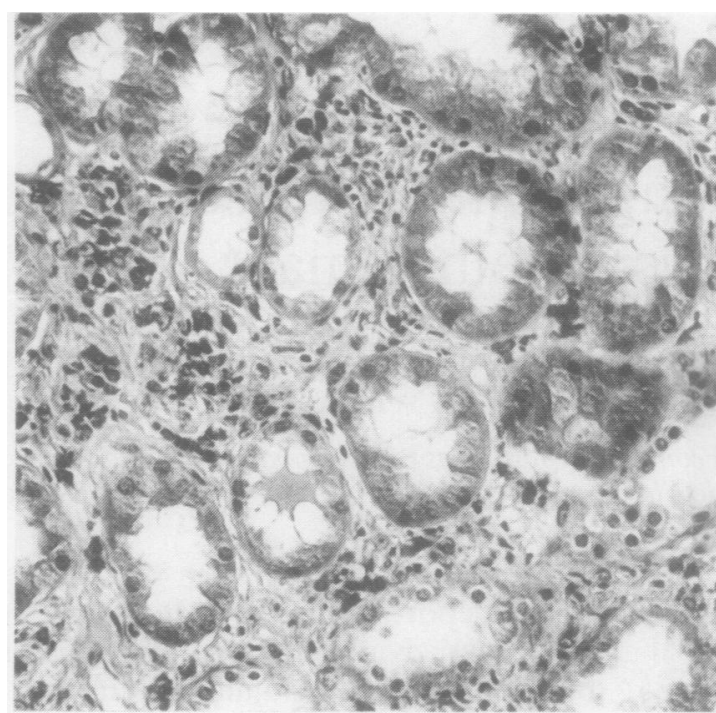

Fig. 3 Kidney biopsy $(\times 210)$. This section shows tubular degeneration and diffuse infiltration.

PATHOLOGICAL OBSERVATIONS

A lymph node biopsy (Fig. 1) showed that the nodal architecture was altered, but the peripheral sinuses remained distinguishable. Patchy infiltrates of the capsular tissue were noticeable. A pleomorphic infiltration contained immunoblasts and a large number of mature plasma cells and lymphocytes. Some germinal centres were preserved. A marked proliferation of small vessels was seen within the infiltrate. Intercellular deposits of eosinophilic material were stained with periodic acid-Schiff 3 reagent. Special stain showed a dense network of $\delta$ reticulin fibres. Immunofluorescence studies confirmed the polyclonal origin of the lymphoproliferation. (The slides were reviewed by Dr Diebold, who concurred.)

A lip biopsy (Fig. 2) showed that about $80 \%$ of the acini had been destroyed by a diffuse, pleomor- $\sigma$ phic infiltrate containing numerous plasma cells, $N$ lymphocytes, and a few immunoblasts. Although $N$ there was no focal organisation, the lesions were $\sigma$ classified as Sjögren's syndrome, stage $4 .^{12}$

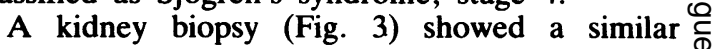
lymphoplasmocytic proliferation. Mature plasma $\mathscr{\mathscr { S }}$ cells were present and tubular sections showed cell $\square$ necrosis and vacuolar degeneration.

\section{Discussion}

The present case meets the current diagnostic $\bar{\sigma}$ criteria of AILD and Sjögren's syndrome. This
Fig. 2 Lip biopsy $(\times 150)$. A minor salivary gland contained a prominent infiltrate lacking focal organisation. 
association has been previously reported in eight instances. In the nine patients the clinicopathological findings of AILD were unremarkable. The sicca syndrome was well documented, gland swelling occurring in five cases. Four patients died within two years.

AILD is known to involve extranodal tissues. Lymphoproliferation in the kidneys is held responsible for renal insufficiency. A similar process may cause eye and mouth dryness. It seems likely that the exocrine gland involvement is a consequence of AILD infiltrate spreading to non-lymphoid tissues, a hypothesis supported in our patient by the striking similarities between lip and kidney biopsies and, in other cases, by the diagnosis of AILD before sicca syndrome. ${ }^{4}{ }^{10}$ This hypothesis should be substantiated by further studies of salivary gland in AILD. In preliminary work a systematic evaluation of exocrine gland in various lymphoproliferative diseases showed a number of lacrymal and salivary dysfunctions. ${ }^{13}$ The alternative hypothesis that AILD develops in a gland involved with Sjögren's syndrome cannot be easily dismissed. A whole spectrum of lymphoproliferative disorders has been reported in Sjögren's syndrome, ${ }^{11}{ }^{14}$ ranging from benign to malignant lymphoproliferations. Furthermore, AILD may be confused with 'pseudolymphoma', described in $1971 .{ }^{11}$ AILD did not gain wide acceptance until $1975 .^{1}$ In one instance the diagnosis was corrected upon reexamination of the slides. ${ }^{8}$

A similar question arises from recent work by Koo et al. ${ }^{15}$ The authors proposed more demanding criteria in order to make a distinction between AILD and another condition in which lymph node biopsies showed some, but not all, of the morphological features of AILD. They called this condition 'atypical lymhoplasmacytic and immunoblastic proliferation' and found that it was often associated with evidence of autoimmune disease. In the same article Koo states that AILD has not been reported in patients with distinct clinically recognisable immunological disease. (Koo reclassified Pierce's case ${ }^{10}$ upon reviewing the slides; he went further by interpreting lymph node changes as indicating an 'abnormal immune response', but the postmortem examination had shown a malignant lymphoma of the heart and Koo's argument does not seem compelling.) In our patient the lymph node biopsy showed all the features of AILD and, kidney lesions ruled out the atypical lymphoid hyperplasia described by Koo.

Even if sicca syndrome precedes AILD we think that the association should be considered as a distinct pathological entity. Four points are relevant to this hypothesis. The mean time (1.6 years) between the diagnosis of sicca syndrome and AILD is significantly shorter than the time between Sjögren's syndrome and pseudolymphoma or lymphoma (nine years). (Pseudolymphoma: 9.0 years, lymphoma: $9 \cdot 1$ years, means of 25 and 30 published cases available to us $(p=0 \cdot 014)$.) The onset of AILD is often acute, resembling infection or drug allergy, or both, unlike the slow onset of pseudolymphoma. The prognosis of AILD is fatal within five to 50 months, and the cause of death is immunodepression, infection, or progression to lymphosarcoma. ${ }^{16}$ Prognosis in pseudolymphoma is better since the disease responds to cytotoxic drugs, though progression to overt malignancy has been reported. ${ }^{17}$ Finally, in our patient and in least one other case ${ }^{6}$ the histological appearance of the lip biopsy was different from the lesions seen in Sjögren's syndrome. The focus score was not applicable, and this now well established diagnostic criterion for Sjögren's syndrome was absent. ${ }^{18}$

\section{References}

1 Frizzera G, Moran E M, Rappaport H. Angio-immunoblastic lymphadenopathy:diagnostic and clinical course. Am J Med 1975; 59: 803-18.

2 Lukes R J, Tindle B H. Immunoblastic lymphadenopathy: a hyperimmune entity resembling Hodgkin's disease. $N$ Engl J Med 1975; 292: 1-18.

3 Davies P G, Fordham J N. Arthritis and angioimmunoblastic lymphadenopathy. Ann Rheum Dis 1983; 42: 516-8.

4 Diebold J, Zittoun R, Tulliez M, et al. Pseudolymphomes et syndromes lymphoprolifératifs malins au cours du syndrome de Gougerot-Sjögren. Sem Hop Paris 1978; 54: 1033-40.

5 Bisson M, Massias P, Segond P, Jacquot J M, Brunaud M D. Association d'une lymphadénopathie angio-immunoblastique et d'un syndrome de Gougerot-Sjögren. Nouv Presse Med 1978; 7: 2393.

6 Patri B, Loison F, Dubrisay J, Vilde F, Diebufd J. Adénopathies lymphangio-immunoblastiques, syndrome sec et sarcome de Kaposi purement viscéral. Ann Med Interne (Paris) 1980; 131: $528-30$.

7 Moore S B, Harrison E G, Weiland L H. Angio-immunoblastic lymphadenopathy. Mayo Clin Proc 1976; 51: 273-80.

8 Le Charpentier Y, Faucher J N, Ghozlan R, et al. Lymphodénopathie angio-immunoblastique (LAI) riche en cellules épithélö̈des révélée par un syndrome de GougerotSjögren: rapports nosologiques des 'pseudolymphomes' du Sjögren avec la LAI (à propos d'un cas d'évolution mortelle). Ann Anat Path 1978; 23: 201-16.

9 Díaz-Jouanen E, Ruíz-Argüelles G J, Vega-Ortiz J M, Villareal G, Alarcón-Segovia D. From benign polyclonal to malignant monoclonal lymphoproliferation in a patient with primary Sjögren's syndrome. Arthritis Rheum 1981; 24: 850-3.

10 Pierce D A, Sterne R, Jaffe R, Zulman J, Talal N. Immunoblastic sarcoma with features of Sjögren's syndrome and systemic lupus erythematosus in a patient with immunoblastic lymphadenopathy. Arthritis Rheum 1979; 22: 911-6.

11 Anderson L G, Talal N. The spectrum of benign to malignant lymphoproliferation in Sjögren's syndrome. Clin Exp Immunol 1971: 9: 199-221.

12 Chisholm D M, Mason D K. Labial salivary gland biopsy in Sjögren's syndrome. J Clin Pathol 1968; 21: 656-60. 
522 Bignon, Janin-Mercier, Dubost, Ristori, Fonck, Alphonse, Sauvezie

13 Pritchard K L, M'Seffar A. Weinstein A, et al. The prevalence of Sjögren`s syndrome in non Hodgkin's lymphoma [Abstract]. Arthritis Rheum 1978: 21: 585.

14 Talal N. Sokoloff L. Barth W F. Extrasalivary lymphoid abnormalities in Sjögren's syndrome (reticulum cell sarcoma. "pseudolymphoma", macroglobulinemia). Am J Med 1967: 43: $50-65$.

15 Koo C H, Nathwani B N, Winberg C D, Hill L R, Rappaport H. Atypical lymphoplasmacytic and immunoblastic proliferation in lymph nodes of patients with autoimmune disease (autoimmune-disease-associated lymphadenopathy). Medicine $\frac{\square}{\infty}$ (Baltimore) 1984; 63: 274-90.

16 Pangalis G A, Moran E M. Nathwani B N, Zelman R J, Kim H, Rappaport H. Angio-immunoblastic lymphadenopathy: long- $\mathscr{\mathscr { S }}$ term follow-up study. Cancer 1983; 52: 318-21.

17 Faguet G B, Webb H H. Agee J F. Ricks W B, Sharbaugh J H. Immunologically diagnosed malignancy in Sjögren`s pseudolymphoma. Am J Med 1978; 65: 424-9.

18 Daniels T E. Labial salivary gland biopsy Sjögren's syndrome: assessment as a diagnostic, criterion in 362 suspected cases. Arthritis Rheum 1984; 27: 147-56. 